\title{
SIGNIFICANCE OF PAP SMEAR IN DIAGNOSING ENDOMETRIAL CARCINOMA
}

\author{
Fauzia Imtiaz, S. Mehmood Hasan, Shabnum Ayub, \\ Afzal Memon and S. A. H. Zaidi
}

\begin{abstract}
OBJECTIVE: To explore the role of cervical cytology in the diagnosis of endometrial disease in postmenopausal women in our set up.

SETTING: Study was conducted at Department of Pathology and Microbiology of The Aga Khan University, Karachi Pakistan during 2004.

METHODS: To assess the correlation between endometrial cells on routine cervical cytology and endometrial carcinoma, 57 Pap smears were taken from postmenopausal women with and without abnormal bleeding. The mean age was $54 \pm 7$ years. The results of cervical cytology were compared and further confirmed with the endometrial histology.

RESULTS: We found a positive association between endometrial cells in Pap smear and carcinoma of the endometrium in six out of 57 patients (11.02\%) while remaining 51 patients (88.98\%) were benign. However, the presence of atypical endometrial cells in Pap smear and the abnormal vaginal bleeding confirmed the diagnosis.

CONCLUSION: The data indicate the importance of further diagnostic evaluation with endometrial sampling in postmenopausal women with endometrial cells seen in Pap smear, especially in abnormal vaginal bleeding.
\end{abstract}

KEY WORDS: Gynaecology. Endometrium. Cervix. Carcinoma. Pap smear. Diagnosis.

\section{INTRODUCTION}

Cervical cytology has engendered a tremendous amount of media coverage in recent years. It is performed by taking Pap smear as screening test for carcinoma of cervix and the identified cells may indicate a precancerous or cancerous process in cervix. However, any abnormal smear must be followed with a careful clinical examination.

Endometrial carcinomas are the most common malignancy of the female genital tract and the third most common cancer worldwide ${ }^{1}$. They make up $97 \%$ of all uterine cancers and arise from the glands within the endometrium ${ }^{1}$. Endometrial hyperplasia is a precursor to the most common gynecological cancers diagnosed in women: endometrial cancer of endometriod histology. It is most often diagnosed in postmenopausal women, but women at any age with unopposed estrogen from any source are at an increased risk for developing endometrial hyperplasia. Hyperplasia with cytological atypia and abnormal uterine bleeding is the most common presentation of endometrial hyperplasia.

Several studies have found a significant correlation between endometrial cells detected on Pap smear and endometrial carcinoma ${ }^{2}$. An association has been reported with normal and atypical endometrial cells on cervical cytology primarily in postmenopausal women. The relationship between these findings on Pap smear and carcinoma of the uterus has been shown on range from $1.0 \%-11.0 \%{ }^{3-5}$. The purpose of this study was to evaluate the correlation between endometrial cells found on Pap smear and the subsequent findings of significant endometrial pathology in our set up.

\section{MATERIAL AND METHODS}

This study was conducted at Department of Pathology and Microbiology of The Aga Khan University, Karachi-Pakistan during 2004. A total of 57 Pap smears were obtained from the women with mean age of $54 \pm 7$ years. They came to the hospital with the presenting complaints of postmenopausal vaginal bleeding. The Pap smear was obtained with Ayre's spatula and immediately fixed in absolute alcohol, stained with Papanicolaou staining procedure. It was screened for any abnormal 
cytology. Suspected cases were confirmed by histological study after taking biopsy.

\section{RESULTS}

The observations were taken on total 57 Pap smears. The mean age of women was $54 \pm 7$ years. Among these 57 Pap smears, 29 (50.9\%) were normal superficial cells pattern (Figure I), 22 (38.6 \%) showed infection on cytology (Figure II) while 6 (10.5 $\%$ ) showed atypical abnormal cells on Pap smear which were suspected of endometrial origin (Figure III). The biopsy samples of these six women were taken to confirm the diagnosis of endometrial carcinoma on histology (Figure IV). The postmenopausal vaginal bleeding was present in 39 (68\%) women while it was absent in 17 (32\%) women. The mean duration of bleeding was 2 weeks. A positive correlation between presence of atypical cells on Pap smear and carcinoma of endometrium was observed at $\mathrm{p}<0.05$ (Table I). These atypical cells were confirmed on histology and the distribution is shown in Graph I.

TABLE I: CORRELATION BETWEEN PAP SMEAR AND POSTMENOPAUSAL BLEEDING

\begin{tabular}{|l|c|c|}
\hline & Pap Smear & PMB \\
\hline Pap Smear & 1.000 & 0.041 * \\
\hline PMB & & 1.000 \\
\hline
\end{tabular}

PMB = Postmenopausal bleeding

*Significance at $p<0.05$

\section{GRAPH I: DISTRIBUTION OF PAP SMEAR FINDINGS}

FIGURE I: PAP SMEAR SHOWS NORMAL

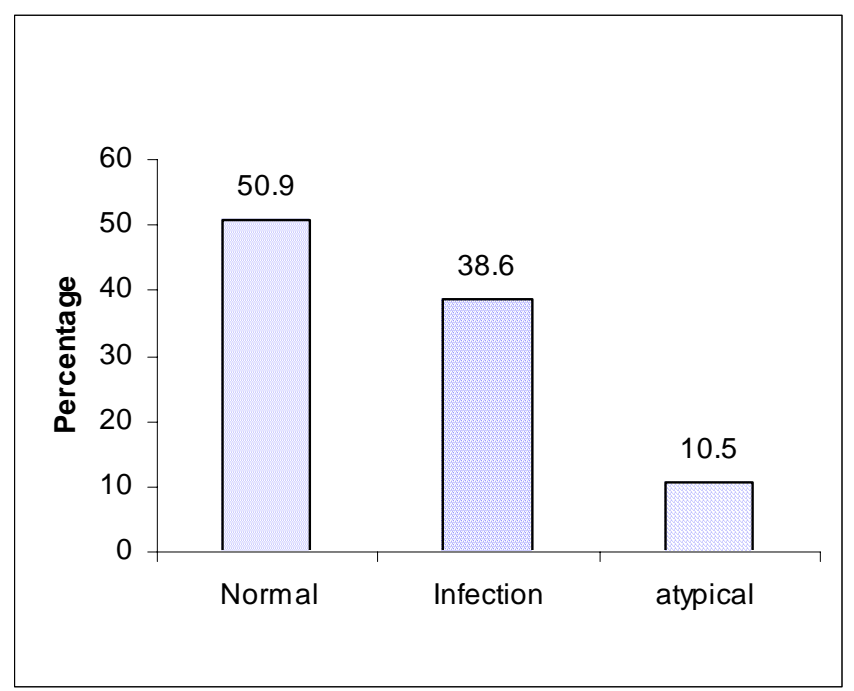

SUPERFICIAL SQUAMOUS CELLS FIGURE II: PAP SMEAR SHOWS INFECTION

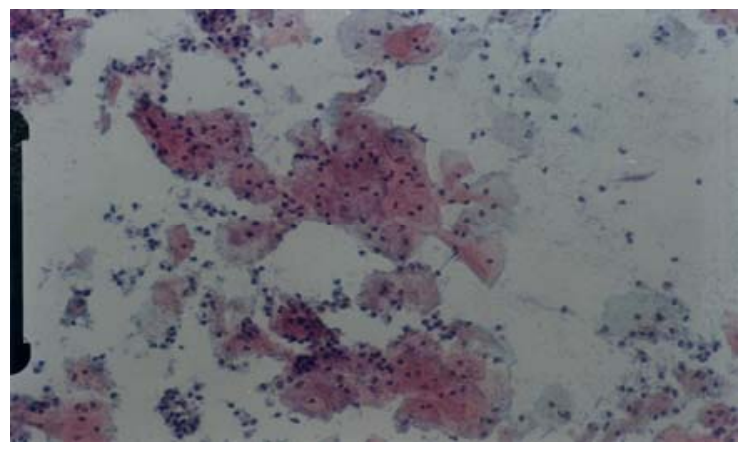

FIGURE III: PAP SMEAR SHOWS ATYPICAL

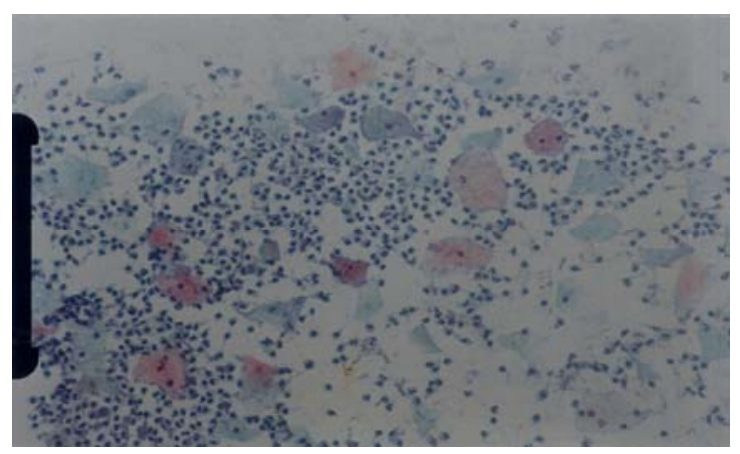

ABNORMAL CELLS

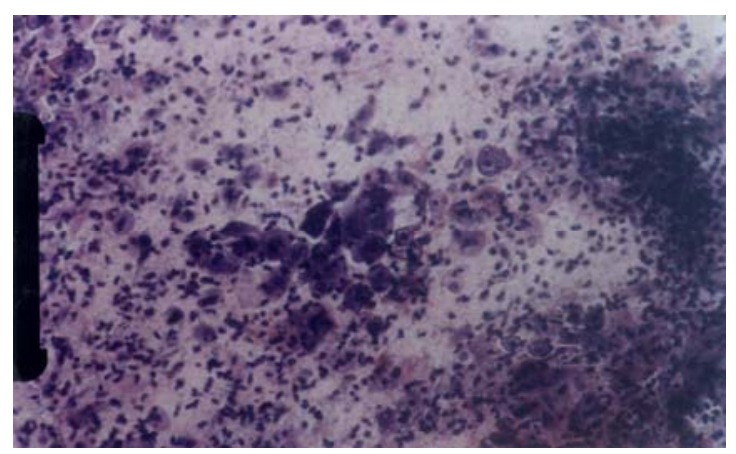

FIGURE IV: HISTOLOGY SHOWS ENDOMETRIAL ADENOCARCINOMA

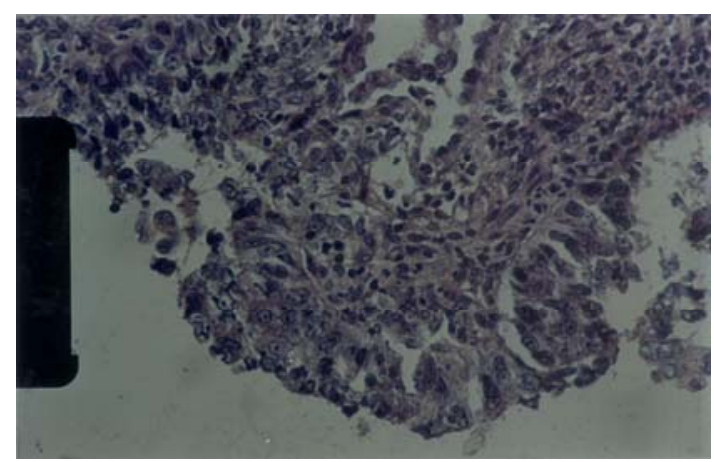




\section{DISCUSSION}

The Pap smear test was introduced by George Papanicolaou about 80 years back and it is now proved to be one of the best procedures for cervical cancer prevention. Most cervical cancers start from an area of dysplastic epithelium which can be detected well by taking good Pap smear ${ }^{6}$. Endometrial cells reported on a Pap smear are a annoying finding in the postmenopausal patients. A study conducted on 227 postmenopausal women especially older than 59 years have showed that benign endometrial cells on a Pap smear may warrant direct endometrial sampling to rule out malignancy ${ }^{7}$.

There is importance of further diagnostic evaluation with endometrial sampling in postmenopausal patients with endometrial cells seen in Pap smear, especially those with abnormal bleeding ${ }^{2}$. Our results also show the correlation between presence of atypical cells on Pap smear and postmenopausal vaginal bleeding. The presence of atypical glandular cells of undetermined significance in cervical smear from women over 50 years was highly predictive of abnormal lesions detected by histological examination. Recently, Obenson and coworker reported that three cancers were detected on histology follow up and the most common lesions were endometrial polyps ${ }^{8}$. Cytohistological correlation of abnormal cervico-vaginal smears indicates that endometrial metaplasia may be associated with the presence of atypical glandular cells ${ }^{9}$. We also confirmed our results on the basis of histological findings.

A prompt and aggressive work up is recommended for those patients who show the atypical glandular cells of undetermined significance on Pap smears. The diagnostic sensitivity of the Pap smear is highest for invasive endocervical adenocarcinoma and lowest for endometrial carcinoma ${ }^{10}$. Presence of adenocarcinoma of endometrium ( $1.4 \%$ of all Pap smears) has also been reported in Saudi population ${ }^{11}$. Abnormal Pap smears are significantly associated with the high grade of tumor and stage II - IV endometrial carcinoma. However, they are not associated with patient's age and depth of myometrial invasion or vascular invasion ${ }^{12}$.

The presence of Pap smear abnormalities correlates positively with known indicators of poor prognosis in endometrial carcinoma of high grade at presentation. This information is most useful in the management of patients of endometrial carcinoma with adjuvant therapy.

\section{CONCLUSION}

The data indicates the importance of further diagnostic evaluation with endometrial sampling in postmenopausal women with endometrial cells seen in Pap smear, especially in abnormal vaginal bleeding. There is no test in medicine which is $100 \%$ accurate. Even, if all the proper collection techniques, specimen handling and screening procedure are utilized, there will still be a false negative (missed lesion) rate of at least $4 \%$. Hence, postmenopausal women need to be educated in our set up as well about the importance of seeking attention if any vaginal bleeding occurs.

\section{REFERENCES}

1. Rose PG. Endometrial carcinoma. N Engl J Med 1996; 335 (9): $640-649$.

2. Kerpsack JT, Finan MA, Kline RC. Correlation between endometrial cells on Papanicolaou smear and endometrial carcinoma. South Med J 1998; 91 (8): 749 - 752.

3. Cherkis RC, Patten SF Jr, Dickinson JC et al. Significance of atypical endometrial cells detected by cervical cytology. Obstet Gynecol 1987; 69 (5): 786 - 789.

4. Cherkis RC, Patten SF Jr, Andrews TJ et al. Significance of normal endometrial cells detected by cervical cytology. Obstet Gynecol 1988; 71 (2): $242-244$.

5. DuBeshter B, Warshal DP, Angel $C$ et al. Endometrial carcinoma: the relevance of cervical cytology. Obstet Gynecol 1991; 77 (3): 458 462.

6. Chang A, Sandweiss L, Bose S. Cytologically benign endometrial cells in the papanicolaou smears of postmenopausal women. Gynecol Oncol 2001; 80 (1): 37 - 43.

7. Howard HJW. Benign endometrial cells in Pap smears associated with endometrial diseases. The J Rep Med 2001; 46: 795 - 798.

8. Obenson K, Abreo F, Grafton WD. Cytohistologic correlation between AGUS and biopsy-detected lesions in postmenopausal women. Acta Cytol 2000; 44 (1): $41-45$.

9. Johnson TL, Kini SR. Endometrial metaplasia as a source of atypical glandular cells in cervicovaginal smears. Diagn Cytopathol 1996; 14 (1): $25-31$. 
10. Raab SS. Can glandular lesions be diagnosed in Pap smear cytology?. Diagn Cytopathol 2000; 23 (2): $127-133$.
11. Jamal A, Al-Maghrabi JA. Profile of Pap smear cytology in the Western region of Saudi Arabia. Saudi Med J 2003; 24 (11): 1225 - 1229.

AUTHOR AFFILIATION:

Dr. Fauzia Imtiaz (Corresponding Author)

Senior Instructor, Department of Pathology and Microbiology

The Aga Khan University, Karachi - Pakistan.

Dr. S. Mehmood Hasan

Department of Pathology

Hamdard College of Medicine and Dentistry, Hamdard University, Karachi.

Dr. Shabnum Ayub

Department of Gynaecology and Obstetrics

Abbasi Shaheed Hospital, Karachi.

Dr. Afzal Memon

Department of Forensic Medicine

Liaquat University of Medical and Health Sciences, Jamshoro, Sindh

Dr. S. A. H. Zaidi

Department of Pathology

Hamdard College of Medicine and Dentistry, Hamdard University, Karachi. 